\title{
ESCRITORES ESCLESIÁSTICOS DEL SIGLO VII: BRAULIO Y TAJÓN DE ZARAGOZA
}

\author{
Jorge M. Ayala \\ Universidad de Zaragoza
}

\section{RESUMEN}

Entre los grandes escritores religiosos de la España visigoda del siglo VII destacan dos obispos de la ciudad de Zaragoza: San Braulio y Tajón. El primero mantuvo una especial amistad con san Isidoro de Sevilla, al que animó a que concluyera el libro de las Etimologías; el segundo es considerado en la Historia de la Teología como un precursor de las Sumas teológicas.

Palabras clave: Braulio, Tajón, Isidoro, Sentencias, Suma Teológica.

\begin{abstract}
Two ecclesiastical writers of 7th century: Braulio and Tajon of Zaragoza. Among the great religious writers of the Visigothic Spain (7th century) two bishops of Zaragoza are distinguished: Saint Braulio and Samuel Tajón. The first maintained a special friendship with Saint Isidore of Seville whom he encouraged to conclude the book Origenes sive Etymologiae; the second is considered as a precursor of the theological «Summae» in the History of the Theology.
\end{abstract}

Key words: Isidore, Braulio, Tajón, «Sententia», «Summa».

Durante la época de dominación visigoda, Zaragoza alcanzó un lugar destacado entre las ciudades hispánicas como centro cultural. Superada la división interna producida por la doctrina priscilianista, y devuelta la ortodoxia católica a la Iglesia zaragozana tras la conversión al arrianismo de una parte del clero, se sucedieron en la sede episcopal zaragozana una serie de obispos, entre ellos Braulio y Tajón, cuya impronta cultural ha transcendido el ámbito local y el meramente eclesiástico, debido a la intervención que mantuvo el primero en la elaboración de las Etimologías de san Isidoro, y al carácter precursor de las «sumas» teológicas que presentan los Cinco libros de las sentencias de Tajón. En la presente exposición vamos a destacar estos dos aspectos de san Braulio y de Tajón. ${ }^{1}$

1 Para una visión actualizada sobre la cuestión del priscilianismo en Zaragoza, pueden verse los trabajo del profesor Eugenio Romero Pose, «Sobre los orígenes del cristianismo en Aragón», Revista Aragonesa de Teología, 3 (1996), pp. 55-70, y de la profesora María Victoria Escribano, «El concilio I de Cesaraugusta», Revista Aragonesa de Teología, 5 (1996), pp. 37-52. 


\section{LA CIUDAD DE ZARAGOZA, UN CENTRO DE CULTURA RELIGIOSA}

Con la exaltación de Zaragoza como ciudad martirial, el poeta Prudencio (s. IV) había elevado a esta ciudad, y también a toda la Hispania, casi al mismo nivel que Roma, patria espiritual del cristianismo. De aquí arranca el ideal hispano que retomarán Pablo Orosio e Isidoro de Sevilla, aunque personificado en la nueva monarquía visigótica. El himno Laus Hispaniae de Isidoro de Sevilla es un canto a los nuevos ideales creados por los godos hispanos, y su Historia Gothorum es un poema en alabanza de los reyes godos frente a los milites romani. Ante el inminente hundimiento de la cultura romana, Isidoro ha encontrado en Prudencio, poeta clásico, cristiano y de origen hispano-romano, justificación a su ideal de Hispania como reino unitario y católico. Esto afectaba indirectamente a Zaragoza por haber sido patria, si no del propio Prudencio, sí al menos de los dieciocho mártires:

Zaragoza es una ciudad de la Hispania tarraconense erigida por César Augusto, quien también le dio el nombre. Por el encanto de su paisaje y sus delicias es la más insigne de todas las ciudades de Hispania, y la más preclara e ilustre por las sepulturas de sus santos mártires. $^{2}$

La idealización poética de Zaragoza y de sus mártires comenzaba a dar sus frutos. Más que un lugar geográfico, Zaragoza se había convertido para la Europa medieval que comenzaba a emerger en un tópico estético y religioso:

Este nuevo título de gloria dio el mismo Cristo a nuestra Zaragoza para goce propio, para que fuese por mucho tiempo el templo consagrado de una mártir en vida. ${ }^{3}$.

\section{SAN BRAULIO, OBISPO DE ZARAGOZA (631-651)}

Este ilustre obispo de la sede episcopal zaragozana está unido a la obra religiosa y cultural de san Isidoro de Sevilla, el hombre que hizo de puente entre la cultura clásica y la medieval. Durante la Alta Edad Media se consideraba completa una biblioteca (armarium) si poseía, junto con la Biblia y Virgilio, a los trasmisores de la antigua cultura: Marciano Capella, Prisciano, Beda, Boecio, Casiodoro y las Etimologías de Isidoro. ${ }^{4}$ Los tres últimos, sobre todo, son considerados como los verdaderos maestros de Occidente. En su haber está la defensa que hicieron del legado de los clásicos greco-romanos y la planificación de la enseñanza según la estructura escalonada de las siete artes liberales (Trivium y Quadrivium), núcleo de la cultura durante gran parte de la Alta Edad Media. La obra de Isidoro Origenes sive Etymologiae es una enciclopedia del saber de su siglo

2 Isidoro de Sevilla, Etimologías, XVI, 1, 66. Ed. y traducción de José Oroz Reta y Manuel-A. Marcos Casquero, introducción de Manuel C. Díaz y Díaz, 2 vols., Madrid, BAC, 1993-1994.

3 . Prudencio, Himno a los dieciocho mártires de Zaragoza, v. 140.

4 É. Gilson, La filosofia en la Edad Media, Madrid, Gredos, 1965, p. 143. 
escrita en veinte libros, y en ella trata de gramática, retórica, matemáticas, música, astronomía, geometría, medicina, jurisprudencia, historia, geología, historia natural, navegación, arquitectura y arte.

Más claramente medieval que Boecio y Casiodoro es Isidoro de Sevilla. Tras el estudio monumental que le ha dedicado Jacques Fontaine, ya no se puede poner en duda. La España visigoda nos hace asistir a los balbuceos del Renacimiento carolingio. Isidoro no es el último enciclopedista romano; sin lugar a duda, Isidoro está entre los fundadores de la Edad Media. $^{5}$

Dada la relación amistosa que existió entre Isidoro y Braulio, es lógico que nos preguntemos por la parte que pudo tener el obispo zaragozano en la obra compiladora y trasmisora del obispo sevillano.

San Braulio nació hacia el año 585 en un lugar que todavía no ha sido determinado. Se suele decir que en Zaragoza o en Osma. Pertenecía a una noble familia de origen hispano-romano, tal vez originaria de Gerona. Su padre, llamado Gregorio, fue obispo. Los hermanos de Braulio fueron Juan, abad del monasterio de Santa Engracia de Zaragoza y posteriormente obispo de la ciudad durante doce años (619-631), el cual sucedió a Máximo (592-619), que puso las bases para hacer del monasterio de Santa Engracia un centro de formación religiosa y humanística. Su otro hermano se llamó Frunimiano, y fue abad del monasterio fundado por san Emiliano (San Millán de la Cogolla), en La Rioja. Tuvo además dos hermanas, Pomponia, abadesa, y Basila, casada con un noble, la cual ingresó en un monasterio al quedar viuda. El nombre de Braulio ha quedado unido a la obra de san Isidoro. Braulio da a entender en sus cartas que vivió en Sevilla y que mantuvo un trato familiar con Isidoro. Posiblemente, tras recibir su primera educación en el monasterio zaragozano de Santa Engracia, Braulio marchó hacia el año 620 a la prestigiosa escuela episcopal sevillana para completar su formación. Así parece deducirse de una carta dirigida a san Isidoro, en la que le dice: «Cuando estábamos juntos, te pedí que me enviaras la sexta década de San Agustín».6

De los escritos de san Braulio sólo se han conservado las Cartas y la Praenotatio a las Etimologías de san Isidoro de Sevilla. Quedan, no obstante, algunos testimonios indirectos que nos permiten conocer la talla intelectual de Braulio. San Ildefonso de Toledo escribe de Braulio que «fue hermano de Juan, a quien sucedió en la sede episcopal y respecto del cual no fue menor en ingenio». ${ }^{7}$ San Fructuoso (m. 665) escribe a Braulio desde las costas atlánticas de Portugal en estos términos: «Entre el ronco oleaje del mar embravecido y los torbellinos del océano y la agitación de los mares nutre las entrañas de mi mente, muchas veces secas, y deleita mis pobres oídos la sola noticias de vuestra fecunda actividad, el que vuestra augusta e incansable ciencia ennoblece a vues-

5 Henri I. Marrou, «Les ars libéraux dans l'antiquité classique», Ars Libéraux et Philosophie au Moyen Âge, Montreal-París, 1969, p. 27; J. Fontain, Isidore de Séville et la culture classique dans l'Espagne wisigothique, París, 1959; F.-Javier Lozano Sebastián, San Isidoro y la filosofía clásica, León, Isidoriana, 1982.

6 Luis Riesco Terrero, Epistolario de San Braulio, Sevilla, Filosofía y Letras, 1975, carta 1.

7 Remitimos a la obra del Dr. Sandalio Aznar, San Braulio y su tiempo. El fulgor de una época, Zaragoza, 1985, p. 68. Es una síntesis documentada sobre la iglesia zaragozana de la época a la que nos estamos refiriendo. 
tra Zaragoza y el que la vida de cada día más floreciente de vuestra excelencia se agiganta en el estudio de la Sagrada Escrituras tanto cuanta es la gloria inextinguible y sincera de buenas obras que os rodea». ${ }^{8}$

La importancia cultural de Braulio, escribe Sandalio Aznar, se revela en el liderazgo que supo abanderar en el movimiento de regeneración cultural del siglo VII. A la producción literaria propia unió un manifiesto y activo deseo de divulgación de los escritos del pasado y de los que en su tiempo se iban produciendo. ${ }^{9}$ Naturalmente, tanto la obra cultural de Isidoro como la de Braulio hay que juzgarlas desde la perspectiva del siglo VII, que es esencialmente religiosa.

Con la nueva situación creada tras la conversión oficial de Recaredo al catolicismo (589), Hispania quedó estabilizada políticamente ý unificada religiosamente. A partir de esta fecha, se nota entre la aristocracia visigótica un mayor aprecio de la literatura clásica y una mayor integración en la vida de las letras y de la Iglesia. Entre las cartas conservadas de Braulio, hay varias que están dirigidas a aristócratas visigodos o hispano-romanos que han adoptado nombres godos: Ataúlfo, Gundesvinda y Givario, Wistremir. Esas cartas están imbuidas de sentido cristiano, signo evidente de que la fuerza vertebradora de la vida cultural no son ya los estudios clásicos sino la cultura religiosa, dirigida fundamentalmente a la formación clerical y monástica. «La formación cultural de la España visigótica es ante todo formación religiosa, cristiana. Aunque en ella encontremos elementos clásicos, éstos quedan asimilados dentro de una perspectiva religiosa». ${ }^{10}$ Por otra parte, la cultura de la Hispania visigótica no fue una cultura de creación sino de conservación y de transformación. «En Braulio no faltan citas clásicas, pero procedentes con frecuencia de San Agustín y, especialmente, de San Jerónimo. Y es que entre los escritores de aquel tiempo era tal el respeto a la tradición que, si para escribir sus ideas del momento tenían una fórmula ya sancionada por la Antigüedad, la tomaban como suya». ${ }^{.1}$

Las ciudades de Sevilla, Toledo y Zaragoza pasaron a ser los principales focos culturales de España. Sevilla, por obra de san Leandro y de san Isidoro; Toledo, por ser la residencia de la monarquía y la sede de los concilios; Zaragoza, por la talla de sus obispos, comenzando por Máximo (m. 619) y siguiendo por Juan, Braulio y Tajón. Bajo su protección funcionó en Zaragoza una escuela episcopal y monacal de formación literaria y teológica, en la que se formaron, entre otros, san Eugenio de Toledo y Fronimiano, abad de monasterio de San Emiliano (San Millán de la Cogolla), en La Rioja. La base material de esta escuela la constituía la biblioteca (armarium), iniciada por el obispo Juan. Han quedado testimonios referidos a esta biblioteca zaragozana:

Se han cumplido ya, si no me engaño, los siete años desde que te pedí los libros de los Orígenes por ti compuestos [...] Ruego pues que te dignes mandármelos transcritos, íntegros, corregidos y bien ordenados». ${ }^{12}$

8 San Braulio, Epistolario, carta 43.

9 Cfr: Sandalio Aznar, o.c., p. 82.

10 Laureano Robles, o.c., p. 10.

11 María Luisa García Sanchidrián, «Braulio de Zaragoza: hombre de vasta cultura y erudición clásica», en Homenaje a la profesora emérita María Luisa Ledesma Rubio, Zaragoza, Prensas Universitarias, 1993, p. 343.

12 San Braulio, Epistolario, carta 5. 
Cuanto a los libros que me habéis mandado os remitiera no los he encontrado duplicados; algunos no los he encontrado siquiera ni en un ejemplar: me he dado cuenta de que habían desaparecido de mi biblioteca, y mis ocupaciones no me han permitido proseguir mi investigación sobre ellos. Pero, si Dios quiere y me acompaña la vida, queda la esperanza de encontrarlos y de enviároslos. ${ }^{13}$

Mas ahora pienso que por divina voluntad, cuando buscaba un libro para algo que se me había ocurrido, al revolver un montón de libros, aquellas notas por largo tiempo perdidas fueron halladas, cuando no las buscaba, pues ya había cesado el deseo de buscarlas, ante la desesperación de ya no encontrarlas. ${ }^{14}$

Dada la actividad cultural existente en Zaragoza, se supone que junto a la biblioteca (armarium) debió de existir un laborioso escritorio (scriptorium), especie de taller para la copia y el arreglo de los códices estropeados, convirtiéndose la «escuela zaragozana» ${ }^{15}$ en un centro de difusión literaria, como lo atestiguan estos documentos. Braulio, estando casi ciego al final de su vida, escribe así al rey Recesvinto:

En efecto, el deplorable estado del códice, que recibí para corregir, puso en orden de batalla a todas sus fuerzas contra la debilidad de mi vista, y en mi esfuerzo por vencerlas, mi vista que empezaba a fallar pareció que se rendía ante el enemigo y en daño propio acrecentaba su debilidad. ${ }^{16}$

Aunque este manuscrito ha sido copiado para otro, sin embargo, como no puedo negarme a tu petición, te lo envío a ti. ${ }^{17}$

San Fructuoso de Braga pide encarecidamente a Braulio que le envíe la Vida de San Emiliano que acaba de escribir, junto con otras obras religiosas y profanas que le indica:

Como en esta región en que vivimos no se encuentran [los libros que indica], suplico encarecidamente a tu merced que enriquezcas este monasterio con las colecciones de Casiano [...] No nos desprecies a nosotros que estamos ya alejados y hundidos en la tenebrosa región de Occidente. ${ }^{18}$

En los escritos de Braulio no se hallan referencias explícitas a la filosofía, ni esquemas que denoten la existencia de un pensamiento creador. Anteriormente hemos indicado que los siglos VI y VII no fueron siglos de creación sino de recopilación, de síntesis y de comentario, preferentemente de obras religiosas. San Isidoro es muy explícito a este respecto cuando, en una carta dirigida a Braulio, le dice lo siguiente:

13 Ibidem, carta 44.

14 San Braulio, carta prefacio a la Vida de San Emiliano, en H. Lynch y P. Galindo, San Braulio, o.c., p. 174.

15 Cfr: Sandalio Aznar, o.c., p. 130.

16 San Braulio, Epistolario, carta 38.

17 Ibidem, carta 16.

18 Ibidem carta 43. 
Ahí te envío, como te prometí, la obra sobre el origen de algunas cosas, compuesta con los recuerdos de antiguas lecturas y comentada en algunos pasajes en el estilo en que escribieron nuestros mayores. ${ }^{19}$

Una vez acabada la pesadilla que fue para la Iglesia católica el priscilianismo y el arrianismo, y que le obligó a defenderse de tales herejías empleando un discurso esencialmente apologético (filosófico-teológico), como quedó patente en el tratado De Anima del obispo Liciniano de Cartagena (m. 603), los obispos centraron su atención en la formación de los sacerdotes, entre los que abundaban los «iletrados». Con este fin se fundaron las escuelas episcopales. Allí vivían vigilados por el obispo y aprendían lo esencial de su oficio: el salterio, cánticos e himnos y el ritual del bautismo. Las escuelas monásticas tenían una orientación más doctrinal que profesional. De estas escuelas salieron los grandes obispos letrados del siglo VII: Leandro, Isidoro, Braulio, Tajón, los dos Eugenios de Toledo, Ildefonso de Toledo, Juan de Biclara y Julián.

No parece que el estudio de la cultura clásica fuera considerado un objetivo prioritario para la formación de los sacerdotes. Así parece deducirse de las palabras de reprensión del obispo Braulio a su sacerdote Tajón, al que parece recriminar la vanidad de su erudición pagana, sin que ello suponga por parte de Braulio estar en contra de misma, antes bien, Braulio se muestra un buen conocedor de la cultura pagana:

Respecto a tu ensayo elaborado con gran aparato, ¡qué fácil me sería, como suele decirse, desmoronarlo de un puntapié, excepto la parte, con perdón de Gregorio, que aunque plagiado, he visto adulterado! Pero, como quiero ser servidor del amor y no perderte, lo dejo todo y no incluyo nada que pueda provocar la risa, para que mis palabras no contengan bromas desagradables, como dice Ovidio, ni parezca, como Apio dice, que ejercito una facundia canina [...] Por ello, queridísimo, también nosotros debemos apartarnos de aquéllos y seguir estos tan dulces ejemplos. ${ }^{20}$

$\mathrm{Si}$, como parece, Braulio se formó intelectualmente en la escuela monástica de Sevilla bajo la dirección de Isidoro, se puede suponer con razón que sus conocimientos de cultura clásica no irían a la zaga de los de su maestro. Lynch da por seguro que los conocimientos clásicos de Braulio eran superiores a los de Isidoro:

[...] porque también yo, como dice Horacio, aprendí las letras y muchas veces aparté la mano de la férula y puede decirse de mí: «Huye lejos de él, lleva heno en el cuerno», y también aquel dicho de Virgilio: «También, yo, padre, lanzo dardos y manejo la espada con valor y las heridas que yo hago hacen brotar la sangre». ${ }^{21}$

Pero, esa superioridad tenía sus limitaciones, como ha mostrado García Sanchidrián: «No pocas veces en el escritor latino Braulio, que es sin duda el mejor conocedor y el que apreció la cul-

19 Ibidem, carta 7.

20. Ibidem, carta 11.

21 Ibidem, carta 11; C.H. Lynch y Galindo, o.c., p. 62. 
tura clásica como tal, su erudición clásica pierde algo de valor al servirse de citas de segunda mano; es decir, de frases estereotipadas y proverbiales que formaban ya parte del acervo de la lengua. Y, claro está, los autores más frecuentemente citados son los eclesiásticos, especialmente los más ricos en doctrinas antiguas. Pero su reputación es mayor en el conocimiento amplísimo que demuestra tener, sobre todo, del Epistolario de San Jerónimo; hemos advertido también alusiones o referencias a las Sátiras de Horacio, a los Fastos de Ovidio y, finalmente, a la Eneida de Virgilio, todas la cuales forman parte, insistimos, del repertorio de San Jerónimo, cuyo dominio de Cicerón y de Virgilio, sin olvidar el Satiricón, es sorprendente». ${ }^{22}$

No es posible asegurar si la biblioteca de los obispos zaragozanos poseía las obras de los autores clásicos. Por lo que respecta a Braulio, «el lenguaje latino escrito en el Epistolario de nuestro obispo cesaraugustano muestra una marcada tendencia a los usos y empleos clásicos, que justifica la afirmación de que el espíritu clasicista de San Braulio es una realidad». ${ }^{23}$

¿Tuvo Braulio alguna parte en la composición de la magna obra isidoriana? Creemos que, si no una participación material, sí parece que Braulio contribuyó con sus estímulos a que el sabio hispalense la llevara a feliz término:

Él [Isidoro] publicó [...] el códice de las Etimologías, obra de gran amplitud, que dividió en títulos, pero no en libros; obra que, por haberla hecho a ruego mío [quem rogatu meo fecit], aunque la dejó imperfecta, yo la he dividido en veinte libros. ${ }^{24}$

Este testimonio está corroborado por otros muchos, en los cuales se ve cómo Isidoro escribió las Etimologías a instancias de Braulio. El obispo zaragozano pide con insistencia a Isidoro que le mande un ejemplar de las Etimologías:

Te pido y ruego con todo encarecimiento que acordándote de tu promesa me envíes el libro de las Etimologías que, según he oído, has terminado con la ayuda de Dios, porque sé muy bien que trabajaste en él en gran parte a instancias de tu siervo. Por tanto sé generoso conmigo en primer lugar. ${ }^{25}$

Pero voy a empezar ya mi exposición. Si no me equivoco, han pasado ya siete años desde que te estoy pidiendo, a lo que recuerdo, los libros de los Orígenes, escritos por ti y tú, cuando estaba contigo, me engañaste con mil evasivas y, después que me separé de ti, no me has contestado al objeto, sino que con sutiles pretextos, diciéndome unas veces que no estaban terminados, otras, que no tenías copias, otras, que mi carta se había perdido y otras muchas excusas, hemos llegado hasta el día de hoy y seguimos sin que mi petición ya ha tenido resultado. ${ }^{26}$

Te hago saber en consecuencia que los libros de las Etimologías, que te solicito, están ya, aunque mutilados e incompletos, en manos de muchos. Por eso te ruego que me envíes una 
copia íntegra, corregida y bien ordenada, no sea que llevado por mi ansiedad, me vea obligado a tomar otros vicios por virtudes. ${ }^{27}$

Isidoro, de camino para asistir al concilio de Toledo, comunica a Braulio el envío de las Etimologias, con el humilde ruego de que las corrija:

Cuando venía de camino te he enviado con otros códices el de las Etimologías y aunque a causa de mi salud, era ya intención ofrecértelo para que lo corrigieras, si lograba llegar al señalado lugar del concilio. ${ }^{28}$

Para la historia de la cultura filosófico-teológica de Aragón es un honor que el nombre de Braulio haya quedado unido para siempre a una de las obras más representativas de la Alta Edad Media: las Etimologías de san Isidoro de Sevilla, una síntesis ordenada del saber de la Antigüedad que sirvió de pauta al Renacimiento carolingio.

\section{TAJÓN, OBISPO DE ZARAGOZA (651-683)}

Son pocos los datos biográficos que han quedado de este ilustre sucesor de Braulio en la sede episcopal zaragozana. En una carta dirigida al obispo san Quírico de Barcelona, a quien dedica los Cinco libros de las sentencias, dice llamarse Samuel, indicio, según algunos, de su ascendencia judía, aunque también podía responder a la costumbre de añadirse un sobrenombre (cognomen) viejotestamentario. ${ }^{29}$ Tajón narra en esta carta las difíciles circunstancias que afectaron a la ciudad de Zaragoza mientras él acababa de escribir su obra de las Sentencias:

Entonces, un hombre detestable y malvado llamado Froya, erigiéndose en tirano y capitaneando a una banda de criminales, se dedicó a atacar al rey Recesvinto, hombre fiel y buen servidor de Dios, y, dejándose llevar por su soberbia, atacó a la cristiana Patria con ánimo de destruirla. Debido a esto, los vascones, gente feroz sublevada en los Pirineos, devastan y asolan la Patria de los Iberos.

Así pues, en estas adversas condiciones que acabo de describir, aunque durante días enteros no se podía hacer nada debido a los crueles peligros que por todas partes nos rodeaban, ni se podía salir [de los muros de la ciudad] a ninguna parte, ni siquiera a cultivar los campos; sin embargo, durante las noches nos dedicamos al cuidado de las cosas espirituales, y con la ayuda de Dios, a partir de los sagrados volúmenes -me refiero a los del papa San Gregorio— extractamos los capítulos de las Sentencias en cinco libros [...]. ${ }^{30}$

27 Ibidem, carta 5.

28 Ibidem, carta 6.

29 Aimé Solignac, «Tajón de Saragosse», en Dictionaire de Spiritualité, fasc. XCLVI-III, París, Beauchesne, 1990, pp. 12-14; José Orlandis, Semblanzas visigodas, Madrid, Rialp, 1992, pp. 128-141.

30. Manuel Risco, España Sagrada, tomo XXXI, Madrid, 1776, pp. 172-73. Se recogen los Sententiarum libri V, de Tajón. 
Tajón se formó religiosa e intelectualmente en el monasterio de Santa Engracia de Zaragoza, en donde coincidió con Fronimiano, hermano de Braulio y abad del monasterio riojano de San Emiliano (San Millán de la Cogolla), y con Eugenio, futuro obispo de Toledo. Tajón fue un hombre erudito, compilador de las Cartas de Braulio y buen expositor de la doctrina cristiana. Tajón ha pasado a la historia de la teología por su obra sobre Los cinco libros de las Sentencias (652-656).

Los escritos de Tajón son un fiel reflejo del método de trabajo empleado en ese siglo y de la mentalidad que lo guiaba. En efecto, el clero visigótico centró el estudio en la comprensión de la Biblia. Por eso predominan entre los escritores visigodos los comentarios a la misma. El propio Tajón cuenta a Eugenio, obispo de Toledo, que también él escribió unos comentarios al Nuevo Testamento Su método de trabajo consistía en «recoger selectivamente» de los escritores anteriores, con el fin de resumir y de abreviar:

Debo advertir al lector de esta obra que tenga en cuenta, como ya he indicado anteriormente, que la mayoría de los testimonios y capítulos de esta obra, colocados en diversos lugares, de la misma manera que fueron hallados han sido expuestos y ordenados por mí. Otros testimonios que [San Gregorio] pareció haber introducido en la parte anterior y posterior de la obra, y que repetidamente los ha ha vuelto a poner con otras palabras y de forma abreviada aunque conservando el sentido, yo he cuidado de unir algunos a los testimonios precedentes, tal como exige la exposición de los mismos, y eliminando otros, en la medida en que lo siguiente se deduce de lo anterior o sirve a su mejor comprensión. Pues si todas las sentencias fueran puestas por separado, excedería ciertamente la magnitud de los volúmenes y atentaría contra el sentido de la brevedad y causaría fastidio al lector con las repeticiones. ${ }^{31}$

Teniendo en cuenta el modo de trabajar de los escritores de la época, la originalidad de Tajón radica en la transformación que sufren los textos copiados al ser combinados según el plan trazado por el nuevo autor. Conviene tener presente este dato para no caer en anacronismos, como es llamar «plagiario» a Tajón. «Tajón no es un plagiario, sino un compilador que reconoce que lo es. No pretende ser original sino ofrecer un buen guía en cuestiones de doctrina, de moral y de lectura bíblica». ${ }^{32}$

Existe una tradición, según la cual el VII Concilio de Toledo dio cuenta de la pérdida de los Morales del papa san Gregorio Magno en Hispania. En vista de lo cual, se acordó en dicho Concilio enviar una embajada a Roma con objeto de adquirir nuevos ejemplares: Braulio, por su parte, cuenta en una de sus cartas que Tajón fue a Roma con ese mismo objeto, enviado por el rey Chindasvinto. Este dato lo confirma Tajón en su carta al obispo Eugenio de Toledo:

Así pues, estando yo en Roma, como buscara con diligencia los volúmenes de [San Gregorio] que faltaban en España, habiéndolos transcrito con mi propia mano, tanta fue la dulzura de sus palabras que inundó mi alma, que descubrí en ella algo especial que no se puede comparar con nada. ${ }^{33}$

31 Ibídem, p. 169.

32 Aimé Solignac, o.c., p. 14.

33 Manuel Risco, o.c., p. 168. 
Braulio pide con insistencia a Tajón que le envíe dichas obras:

Y una cosa, que me es casi más necesaria que todas las demás y aquí había pasado por alto, voy a pedirte: que me envíes rápidamente para copiarlos los códices de comentarios del papa Gregorio, que todavía no existían en España y por tu esfuerzo y empeño fueron traídos aquí de Roma. ${ }^{3+}$

El viaje de Tajón a Roma tuvo lugar en el año 646. Desde la Ciudad Eterna escribía alborozado en estos términos:

Hemos visto, sí, a nuestro Gregorio en su sede romana, no con la visión natural sino con los ojos de la mente. Lo hemos visto con sus notarios y familiares, los cuales le mostraron una dedicación fiel con su ministerio corporal. Todo cuanto me contaron sobre sus virtudes y otras muchas cosas que yo sé, las manifestaré brevemente y con pocas palabras. ${ }^{35}$

Los Cinco libros de las Sentencias es la obra más representativa de Tajón. Como su propio nombre indica, se trata de una obra de recopilación y de síntesis de la doctrina (Sententiae) de los Santos Padres. El obispo zaragozano recuerda el carácter de resumen que tiene su obra:

Lo que anteriormente expusimos con comparaciones divulguémoslo ahora con palabras más claras. La exposición que sigue a continuación trata de los opúsculos de ese santísimo varón [san Gregorio], llenos de certeza a pesar de su brevedad, pues juzgué necesario publicar algo sobre sus obras.

Así pues, el desdeñoso al que no le gusta leer, y al aplicado al que tal vez le gusta leer pero no puede poseer tantos volúmenes, no menosprecie el trabajo de nuestra breve obra y no retrase la lectura de este manual. ${ }^{36}$

En la composición de esta obra Tajón sigue de cerca la estructura del libro que san Isidoro había escrito casi con idéntico título: Sententiarum libri tres, o De Summo bono, pero introduciendo algunas variaciones: cinco libros en lugar de tres, ampliación de la temática y mejor sistematización. Desde luego, Isidoro gana a Tajón en creatividad, pues mientras éste depende literalmente de los autores que extracta (san Agustín y san Gregorio Magno), Isidoro resume por cuenta propia y lo transforma. Más aún, Tajón depende de Isidoro. El obispo zaragozano no ocultó su dependencia de Isidoro, pero ciertamente no tuvo el valor de ser tan explícito al respecto como lo había sido al referirse a san Agustín y a san Gregorio Magno. «Tajón parte de Isidoro, resume a Gregorio y complementa con Agustín, de quien dice expresamente que toma no poco. El único a quien no menciona después de haberlo copiado es Isidoro de Sevilla». ${ }^{37}$

34 San Braulio, Epistolario, carta 42.

35 José Risco, o.c., p. 167.

36 Ibídem, pp. 167 y 174.

37 Laureano Robles, «Tajón de Zaragoza, continuador de Isidoro», Saitabi, 21 (1971), p. 23. 
Los últimos años de la vida de Tajón se pierden en el silencio de los siglos. Se sabe que asistió a los Concilios VIII (653) y IX (655) de Toledo, y que falleció en torno al año 683, siendo sustituido en la sede episcopal de Zaragoza por el obispo Valderedo (680-701).

Hay motivo para pensar que Tajón fue un obispo admirado y de gran influencia en la iglesia hispano-visigoda, porque, un siglo después de su muerte, los mozárabes forjaron una leyenda (Chronica Muzarabica, siglo VIII) en torno a su viaje a Roma con el fin de copiar las obras de Gregorio Magno y traerlas a Hispania. El escritor mozárabe (un anónimo clérigo hispano) dejó volar libremente la imaginación y transformó la contemplación intelectual de Gregorio Magno de que habla Tajón en una visión sobrenatural, rodeada además de extraordinarias y fantásticas circunstancias (Visio Taionis). Otros historiadores fueron agregando nuevos pormenores, como ocurre en la Historia Gótica, de Ximénez de Rada, según la cual la decisión de enviar a Tajón a Roma fue tomada por el rey Chindasvinto y el Concilio VII de Toledo (18-X-646), conmocionados porque el manuscrito de los Morales de Gregorio Magno había desaparecido de Hispania («una noticia a todas luces inexacta»). Mas el núcleo de la leyenda había surgido muy pronto, en los albores de la dominación islámica y dentro del ambiente peculiar de los mozárabes de Al-Andalus, ansiosos de hallar razones para la esperanza. La credulidad del hombre medieval y su afición a lo maravilloso o extraordinario explican el éxito que alcanzó el relato de la que fue llamada Visio Taionis; y que Tajón consiguiera con su leyenda mucha más fama de la que pudo lograr con las realidades históricas de su vida. ${ }^{38}$

Por último, existe otra leyenda, esta vez con más fundamento que la anterior, según la cual Tajón sería un precursor del Maestro de las Sentencias, Pedro Lombardo. El hecho de que el obispo zaragozano escribiera una obra con el título de Cinco libros de las Sentencias, ha llevado a pensar a algunos admiradores suyos, que Tajón se movía en la misma línea que lo haría después Pedro Lombardo. Sin embargo, las Sentencias de Tajón no tienen el mismo sentido ni desempeñan la misma función que las Sentencias de Pedro Lombardo. Aunque ambos empleen la misma denominación, el significado de la obra es distinto. En efecto, entre los siglos V-VII la palabra sententia cambia su sentido originario de «sentencia jurídica» 0 «definición dogmática» por el de «florilegio» 0 «síntesis ordenada» de doctrinas de los Santos Padres y de escritores eclesiásticos. El florilegio (flores, excerpta, defloratio) es una colección de cuestiones (sentencias) sacadas del texto patrístico al hilo de la lectura del mismo. Posteriormente, las cuestiones fueron ordenadas según los argumentos y sus conexiones racionales, a las cuales se añadían comentarios de los maestros. De aquí surgen las Sentencias de Pedro Lombardo, de san Anselmo y de otros muchos. En el siglo XII las Sentencias se conviertieron en la Summa o colección de Sentencias con las que se trataba de exponer y definir la verdad de la doctrina cristiana o de alguna doctrina. En el siglo XIII, la Summa era ya una ordenación sistematizada y acomodada para su estudio (encyclopedia synthetica paedagogica). La Summa theologica de santo Tomás de Aquino representó en su tiempo el máximo exponente de sistematización y de sentido pedagógico.

Aunque Tajón no poseyó la técnica sistematizadora de los escritores escolásticos, el obispo zaragozano poseía una técnica que le hace ser superior incluso al mismo san Isidoro y, por tanto, 
ser merecedor de una mención entre los precursores del método escolástico: «La obra de Tajón es más sistemática que la de Isidoro. Es un manual, metódicamente mejor concebido, mejor organizado; pero no llega a ser perfecto. Aún hay capítulos un tanto desplazados o forzada su inserción dentro del esquema general que trazara. Comparado el esquema de Tajón con el que seguirán posteriormente los manuales medievales, podemos ver que hay una mayor coincidencia sistemática y metodológica. ${ }^{39}$

Jorge M. Ayala

Departamento de Filosofía

Facultad de Filosofía y Letras

Universidad de Zaragoza

E-50.009 ZARAGOZA 